\title{
Long-term Performance Evaluation for lonospheric Delay Correction of BeiDou Navigation Satellite System
}

\author{
Chen Liu ${ }^{1}$, Yi Jiang ${ }^{1}$, Ye Chen ${ }^{1}$, Ao Xu ${ }^{2 *}$, Junpeng $\mathrm{Li}^{1}$ and Wei Wang ${ }^{1}$ \\ ${ }^{1}$ Beijing Satellite Navigation Center, Beijing, 100094, China \\ ${ }^{2}$ Satellite Environment Center, Ministry of Environmental Protection, Beijing, 100094, China
}

\begin{abstract}
Ionospheric delay is one of the main errors in the satellite navigation and positioning system. At present, ionospheric delay correction model and grid ionospheric information are provided to correct the error in BeiDou Navigation Satellite System (BDS). The ionospheric delay correction model is the Klobuchar model with 8 parameters at the geographic latitude for basic navigation. Grid ionospheric information is the ionospheric grid map covering China region for enhanced services. The dual-frequency pseudo-range combination data and ionospheric data from 2013 to 2018 have been used to make comprehensive assessments of the correction performance of BDS Klobuchar model and ionospheric grid information. The average correction rate of ionospheric grid information is about $85 \%$, and the average correction rate of BDS Klobuchar model is about $73 \%$. The correction accuracy of BDS Klobuchar model varies little, and the ionospheric grid information has a single-peak structure. The correction accuracy in summer and autumn is slightly higher than that in winter and spring. Changes in solar activity have a greater impact on BDS Klobuchar model correction bias. Ionospheric grid information owns relatively strong antidisturbance ability, and BDS Klobuchar model also has a definite anti-disturbance capability compared with the GPS Klobuchar model.
\end{abstract}

\section{Introduction}

Since December 27, 2018, the Primary System of BDS global system has been completed to provide service available worldwide, including countries and regions participating in the "Belt and Road Initiative" [1]; the goal is to comprehensively complete the deployment of BDS global system with the launching of 30 satellites by around 2020, in which BDS will provides basic navigation services, short message communication services and satellite-based augmentation services, international search and rescue services, precise point positioning service, through various types of satellites. By 2035, with BDS as the core, a more comprehensive, more integrated and intelligent national integrated positioning, navigation and time (PNT) system will be completed [1-2]. However, before the comprehensive completion and deployment of BDS global system, BDS regional system has been playing an irreplaceable role, which is the key to ensure the transition from regional services to global services. Because BDS regional system provides continuous without interruption positioning, velocity measurement, timing and short message communication services for users in the Asia-Pacific region, and wide-area differential services for users in China [2].

The influence of ionosphere on satellite navigation and positioning system is mainly reflected in Doppler shift, signal amplitude attenuation, phase flicker effect, signal modulation code group delay, carrier phase lead, magnetic storm and ionospheric error on differential positioning $[3,4]$ The ionospheric delay error is one of the main sources of error affecting satellite navigation and positioning. Whether the error caused by the ionospheric delay can be accurately corrected directly affects the accuracy of navigation and positioning.

At present, the basic services of major satellite navigation systems provide ionospheric models to improve positioning accuracy. For example, Galileo uses the NeQuick ionospheric model, both GPS and BDS regional system use Klobuchar ionospheric models, BDS global system uses the BDGIM ionospheric model [5], while GLONASS has no supporting ionospheric model, and generally uses the Klobuchar ionospheric delay of GPS to estimate the ionospheric delay of GLONASS measurements for single-frequency users [6]. At the same time, the Beidou satellite navigation system integrated the basic navigation service and the enhanced service, and released the grid ionospheric information of the

*Corresponding author’s e-mail: 791387368@qq.com 
high update frequency for users, which effectively improved the positioning accuracy.

The BDS Klobuchar model has been evaluated since the service of BDS. And the evaluation of grid ionospheric information also appeared in the latter stage. Zhang et al. evaluated the accuracy of the BDS Klobuchar model with the ionospheric data of May 2012 by using the GIM data from CODE, with results that the correction deviation in China is about 9TECU, and the correction rate is over 70\% [7]. Sun et al analyzed the correction accuracy of BDS Klobuchar model, with a result that the correction deviation of mid-latitude is about 3.7 TECU in July 2012 [8]. Li et al. evaluated the accuracy of the BDS Klobuchar model from September to November 2012, and concluded that the correction rate was $80 \%$ in the day and $75 \%$ at night [9]. Cheng and Jia estimated the correction accuracy of the BDS Klobuchar model by using CODE data and dual-frequency pseudo-range combination to evaluate the data from day 4 to 7 of 2013 , which was about $50 \%$ [10]. The data from June 1 st to 30th in 2016 was analyzed to estimate the accuracy of grid ionospheric information, ionospheric model and double-frequency ionospheric correction [11]. Wu et al. used the data in 2012 to make simple analysis and assessment of the correction deviation of grid ionosphere information. The RMS of the COMPASS grid ionospheric correction accuracy is better than 2.34TECU in most regions of the Chinese mainland, and the availability is better than $95 \%$ except in the northeast, northwest and outside China [12].

In addition, the ionosphere is subject to periodic changes in the sun as well as changes in day and night, seasons, and solar activity [13-14]. Moreover, it is highly susceptible to the interference of spatial environmental factors, which results in acyclic changes. The solar wind caused by the stream of particles from the solar activity will interact with the earth's magnetic field and ionosphere, resulting in magnetic storms, ionosphere storms, thermosphere storms and high-energy particle storms [4]. These natural phenomena will significantly affect the number of charged particles around the earth, leading to severe disturbances in the ionosphere for several hours to several days, which will have a significant impact on the daily changes of the ionosphere and bring severe challenges to the ionosphere correction of satellite navigation system. The abilities of BDS Klobuchar model and grid ionospheric information are analyzed respectively in the literature $[15,16]$. However, they only studied the anti-disturbance capability of ionospheric grid information, but did not consider the anti-disturbance capability of the BDS Klobuchar model.
It can be seen from studies in recent years that, when evaluating the beidou Klobuchar ionospheric model, on the one hand, the selected data are generally short in time; On the other hand, data of different time are selected for evaluation, and the difference of correction ability is relatively large. Similarly, when evaluating the ionospheric grid information of grid dots, the data selection span is short and all are in the period of calm solar activity. In order to evaluate beidou's ionospheric delay correction ability more objectively, the selected data should include both the normal and disturbance ionospheric state during the ionospheric activation period and the ionospheric quiescence period. Therefore, this paper will use the long-term data from 2013 to 2018 to comprehensively and objectively evaluate the ionospheric delay correction ability of BDS. Given the short service time of BDGIM ionospheric model for BDS global system, it is hard to objective comprehensive evaluation of it. Therefore, there are only grid ionospheric information and BDS Klobuchar model evaluated in this paper.

\section{BDS Klobuchar model}

The BDS Klobuchar ionospheric model has eight model parameters. By using these eight parameters and the geographic latitude of the puncture point, the ionospheric delay in the vertical direction at the puncture point can be calculated, which can be converted into the ionospheric delay on the propagation path by the projection mapping function. The equation is as follows [17].

$$
T=\left\{\begin{array}{cl}
A_{1} & ,\left|t-A_{3}\right|>\frac{A_{4}}{4} \\
A_{1}+A_{2} \cos \left(\frac{2 \pi\left(t-A_{3}\right)}{A_{4}}\right), & \left|t-A_{3}\right| \leq \frac{A_{4}}{4}
\end{array}\right.
$$

Among them,

$$
\begin{aligned}
& A_{2}= \begin{cases}\sum_{i=0}^{3} \alpha_{i}\left(\phi_{M}\right)^{i} & A_{2} \geq 0 \\
0 & A_{2}<0\end{cases}
\end{aligned}
$$

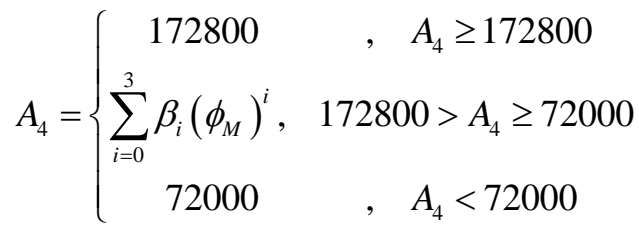


In the above equations, $T$ is the vertical delay in seconds; $A_{1}$ is the night vertical delay constant, and the value is $5 \times 10^{-9} \mathrm{~s} ; A_{2}$ is the amplitude of day cosine function; $A_{3}$ is the time of the peak of the total number of electrons, and the value is $50400 \mathrm{~s}$; $A_{4}$ is a cosine function period of not less than 72,000 s and not more than $172800 \mathrm{~s}$; $t$ is the location at the ionospheric puncture point $\mathrm{M}$ in seconds; $\alpha_{i}$ and $\beta_{i}(\mathrm{i}=0,1,2,3)$ as model correction parameters, and according to the solution of the GNSS dualfrequency observation data of China regional network, the group is updated every two hours. $\varphi_{M}$ is the geographic latitude at the ionospheric puncture point, semicircle.

The mapping functions used in the BDS Klobuchar ionosphere modelare as follows $[17,18]$.

$$
f_{B D S}=\frac{1}{\cos z}
$$

In the formula, $z$ is the zenith distance at the piercing point of the ionosphere.

\section{Ionospheric Grid Information}

The grid of ionospheric information covers 70 to 145 degrees east longitude and 7.5 to 55 degrees north latitude divided by $5^{\circ} \times 2.5^{\circ}$ to 320 IGPs, with an update frequency of 6 minutes time. When IGP $\leq 160$, the corresponding longitudes and latitudes are: $\mathrm{L}=70$ $+\operatorname{INT}((\mathrm{IGP}-1) / 10) \times 5$, and B $=5+(\mathrm{IGP}-\mathrm{INT}((\mathrm{IGP}-$ $1) / 10) \times 10) \times 5$. Where, INT $(*)$ refers to round down. When IGP > 160, the corresponding longitudes and latitudes are: $\mathrm{L}=70+\mathrm{INT}((\mathrm{IGP}-161) / 10) \times 5$, and $\mathrm{B}$ $=2.5+($ IGP-160-INT $(($ IGP-161) $/ 10) \times 10) \times 5$.

The value in ionospheric grid information is in the scale factor of 0.125 and with unit of meters, expressing the vertical ionosphere delay of the grid point on B1I frequency. The effective value range is from 0 to 63.625 meters. If the value is 63.750 meters or 63.875 meters, the IGP is not monitored and not available respectively.

The vertical ionosphere delay at the Ionospheric Puncture Point (IPP) is calculated by interpolating the grid value around the IPP from ionospheric grid information. Interpolation can be performed using the spatial bilinear interpolation method given in [19-20], when at most one point surrounding the IPP is not monitored or not available. It should be noted that the weight of the unmonitored or unavailable grid points is zero when only 3 grid points are available. It is by multiplying by the scaling factor $k=f_{1}^{2} / f_{i}^{2}(i=2,3$; where $f_{\mathrm{i}}$ is the nominal carrier frequency of the $\mathrm{B}_{i}$ signal with the unit of MHZ) to be converted to the ionosphere delay of other frequency points.

\section{Evaluation strategy}

In this paper, Vertical Total Electron Content (VTEC) obtained by the dual-frequency solution would be used as a reference value for evaluation. Dualfrequency solution for ionospheric VTEC adopts the method of consistent with the literature [21].

The ionospheric grid information updates every 6 minutes, and that received at time $t_{0}$ is used to correct the ionosphere delay in the next 6 minutes. Similarly, parameters of BDS Klobuchar model updates every 2 hours, and those received at time $T$ ( $T$ is the hour.) are used to correct the ionosphere delay in the next 2 hours. Therefore, we use the data of $t_{0} \sim t_{0}+6$ minutes to evaluate the ionospheric grid information received at time $t_{0}$, and the data of $T \sim T+2$ hours to evaluate the parameters of BDS Klobuchar model received at time $T$.

The specific evaluation process is as follows

a. Calculate the geographic latitude and longitude of the IPP using Equation 5 and Equation $6[22]$.

$$
\begin{gathered}
\phi_{M}=\arcsin \left(\sin \phi_{u} \cos \psi+\cos \phi_{u} \sin \psi \cos A\right) \\
\lambda_{M}=\lambda_{u}+\arcsin \left(\frac{\sin \psi \sin A}{\cos \phi_{M}}\right)
\end{gathered}
$$

Where, $\lambda_{u}$ is the user's geographic longitude in the unit of arc, and $\phi_{u}$ is the user's geographic latitude in the unit of arc; $\psi$ is the geocentric angle in the unit of arc between the user and the IPP; $A$ is the satellite azimuth in the unit of arc.

b. Use the rule to determine if the IPP is available for performance evaluation of ionospheric grid information, which the ionospheric grid information is effective for interpolation when at most one point surrounding the IPP is not monitored or is not available. If the VTEC at the IPP can be interpolated by ionospheric grid information, the IPP participates in the assessment, otherwise it will not participate. However, all IPPs within the service area participate in the accuracy evaluation of the BDS Klobuchar ionospheric model.

c. Calculate the VTEC values of IPP participating in the assessments by dual-frequency solution.

d. Calculate the VTEC values of IPP participating in the assessment by Equation 1 with 
the parameters of BDS Klobuchar model and the spatial bilinear interpolation method with ionospheric grid information.

e. Calculate the correction accuracy of IPPs. The correction accuracy is obtained by using Equation 5 and Equation 6 and the index includes the correction rate Rate and correction bias Bias.

$$
\begin{gathered}
\text { Rate }=1-\frac{\left|V T E C_{\text {assess }}-V T E C_{\text {ref }}\right|}{V T E C_{\text {ref }}} \times 100 \% \\
\text { Bias }=\left|V T E C_{\text {assess }}-V T E C_{\text {ref }}\right|
\end{gathered}
$$

Where, $V T E C_{\text {assess }}$ is the VTEC of IPP participating in the assessment for BDS Klobuchar model or ionospheric grid information, and $V T E C_{\text {ref }}$ is the ionospheric reference ionospheric VTEC value replaced with the VTEC of IPP participating in assessment by dual-frequency solution.

f. Calculate the correction accuracy of models. The correction accuracy of the BDS Klobuchar model is the average correction accuracy of all IPPs in the service area using the BDS Klobuchar model. The average correction accuracy of the IPPs in the grid block surrounding the IGP is obtained as the accuracy of the IGP.

\section{Data}

The ionospheric delay varies with the change of solar activity, and the period is up to 11 years. It means that the time span for evaluation should be over five and a half years, in order to comprehensively and objectively evaluate the correction accurate of the ionospheric model.

The dual-frequency observations from continuous dual-frequency receivers distributed throughout China, the BDS Klobuchar model parameters from D1 navigation message and the ionospheric grid information from D2 navigation message from 2013 to 2018 , including both the normal period and the ionospheric disturbance period, were adopted as follow-up experimental data. Then, the VTEC via B1B2 dual-frequency observations was calculated as the reference value in the performance evaluation of ionospheric grid information.

\section{Results and discussion}

\subsection{Daily change of correction performance}

Figure 1 and Figure 2 respectively show the daily change of correction bias and rate using BDS Klobuchar model from 2013 to 2018 at UTC. Since the model parameters are updated every 2 hours, the correction bias and rate using BDS Klobuchar model are calculated every 2 hours. The average correction bias and rate are the average correction bias and rate of all the IPP throughout the service area during this period of time per day in a year respectively.

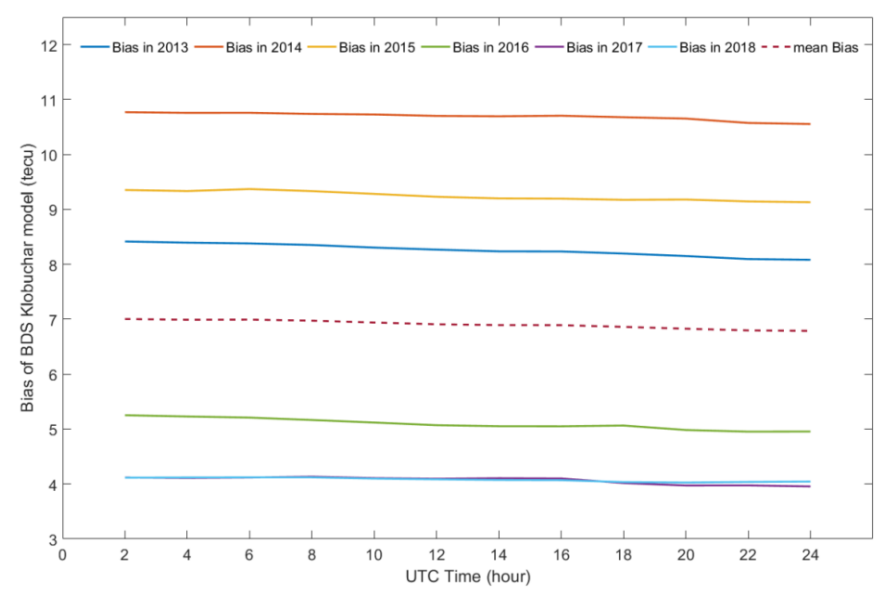

Figure 1. Daily change of correction bias using BDS Klobuchar model from 2013 to 2018. Since the model parameters are updated every 2 hours, the correction bias is calculated every 2 hours. The average correction bias is the average correction bias of all the IPP throughout the service area during this period of time per day in a year.

Figure 1 shows that the correction bias using BDS Klobuchar model is slightly higher during the day in China (about UTC 0:00-12:00) than at night in
China (about UTC 12:00-24:00), with a difference of about 0.3 TECU. It can be observed that the average correction bias using BDS Klobuchar model is about 
7 TECU. However, the differences between correction bias in different years are comparatively greater. The larger bias (about 11 TECU) appears in the active year of solar activity, and the smaller bias (about 4 TECU) appears in the quiet year of solar activity. Figure $\mathbf{2}$ shows that the correction rates using BDS Klobuchar model are slightly higher at night than during the day, with a difference of about $0.5 \%$. The average correction rate using BDS Klobuchar model is about $73 \%$. However, the differences between correction bias in different years are relatively greater. The maximum (about 75\%) appears in 2016 (an intermediate year of solar activity), and the minimum (about 69\%) appears in 2018. The reason is probably that the nighttime ionospheric electron content in an intermediate year of solar activity is close to the nighttime constant value of the Klobuchar ionospheric model, while those in the active or quiet year of solar activity are away from the nighttime constants of the Klobuchar ionospheric model.

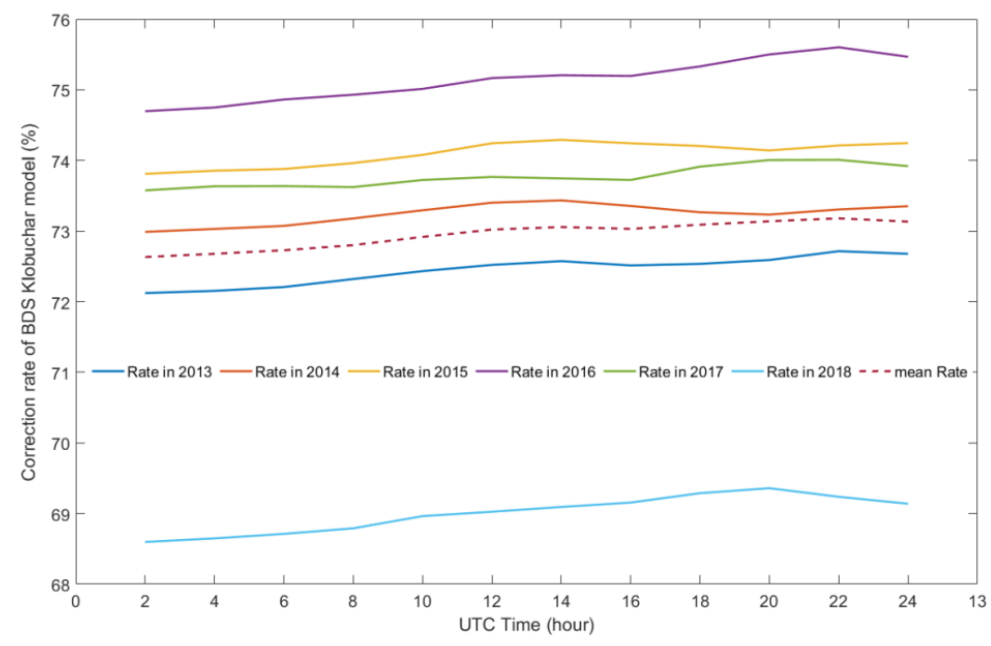

Figure 2. Daily changes in rates using BDS Klobuchar model from 2013 to 2018. Since the model parameters are updated every 2 hours, the correction rate is calculated every 2 hours. The average correction rate is the average correction rate of all the IPP throughout the service area during this period of time per day in a year.

Figure 3 and Figure 4 respectively show the daily changes in correction bias and rate using ionospheric grid information from 2013 to 2018 at UTC. Since the model parameters are updated every 6 minutes, the correction bias and rate using ionospheric grid information are calculated every 6 minutes. The average correction bias and rate are the average correction bias and rate of all the IPP involved in the assessment throughout the service area during this period of time per day in a year respectively. Figure 3 shows that the correction bias of ionospheric grid information are higher during the day than at night with a difference of about $0.5 \mathrm{TECU}$ in the quiet year of solar activity and of about 1.5TECU in the quiet year of solar activity. There are max values at about 8:00 UTC in all years. There is a relatively gentle change at night, especially in the quiet year of solar activity. Moreover, the differences between correction bias in different years are relatively greater. The larger bias appears in the active year of solar activity, and the smaller bias appears in the quiet year of solar activity. The average correction bias using ionospheric grid information is about $2.4 \mathrm{TECU}$.

Figure 4 shows that the correction rates using ionospheric grid information are higher during the day than at night, with a difference of about $8 \%$. The maximum appears at about 6:00 UTC, and the minimum appears at about 21:30 UTC. However, the differences between correction bias in different years are relatively greater, with a max difference of about $4 \%$. The average correction rate using ionospheric grid information is about $84 \%, 11 \%$ higher than the one using BDS Klobuchar model. From the analysis, correction bias and percentage of ionospheric grid information are higher than those during the day night, for the reason that the mean VTEC as the reference value and correction bias both change over time, although the VTEC and bias has a relatively consistent trend, however the VTEC changes proportion bigger, which leads to that the correction percentages with large bias are still bigger in numerical value. 


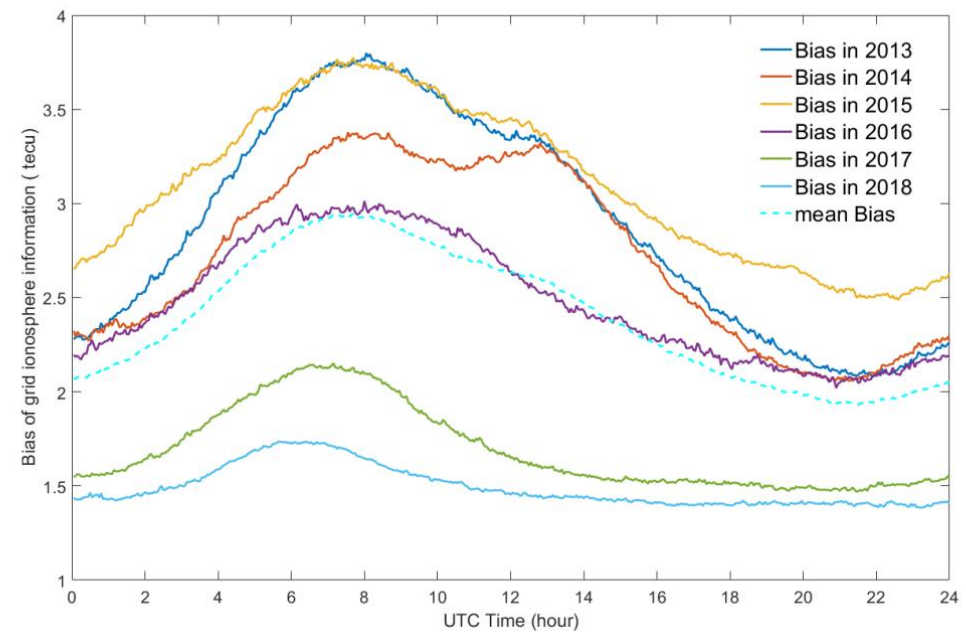

Figure 3. Daily changes of correction bias using ionospheric grid information from 2013 to 2018 . Since the model parameters are updated every 6 minutes, the correction bias is calculated every 6 minutes. The average correction bias is the average correction rate of all the IPP throughout the service area during this period of time per day in a year.

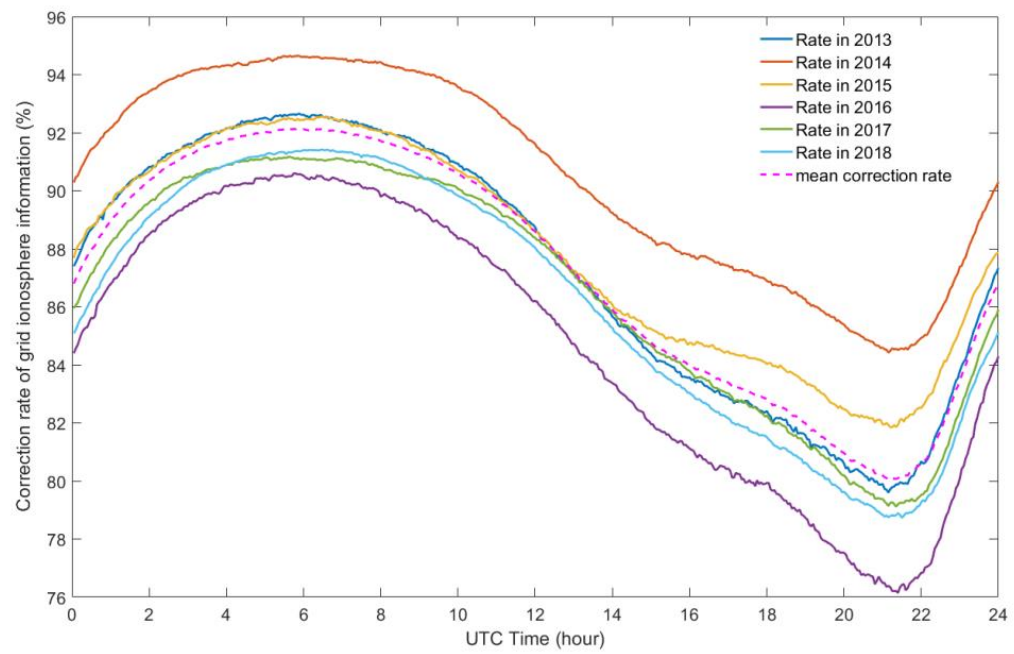

Figure 4. Daily changes of correction bias using ionospheric grid information from 2013 to 2018 . Since the model parameters are refreshed every 6 minutes, the correction rate is calculated every 6 minutes. The average correction rate is the average correction rate of all the IPP throughout the service area during this period of time per day in a year.

\subsection{Seasonal change of correction performance}

Figure 5 and Figure 6 respectively show the daily distribution of corrections bias and correction rates of BDS Klobuchar model and ionospheric grid information in 2018. 


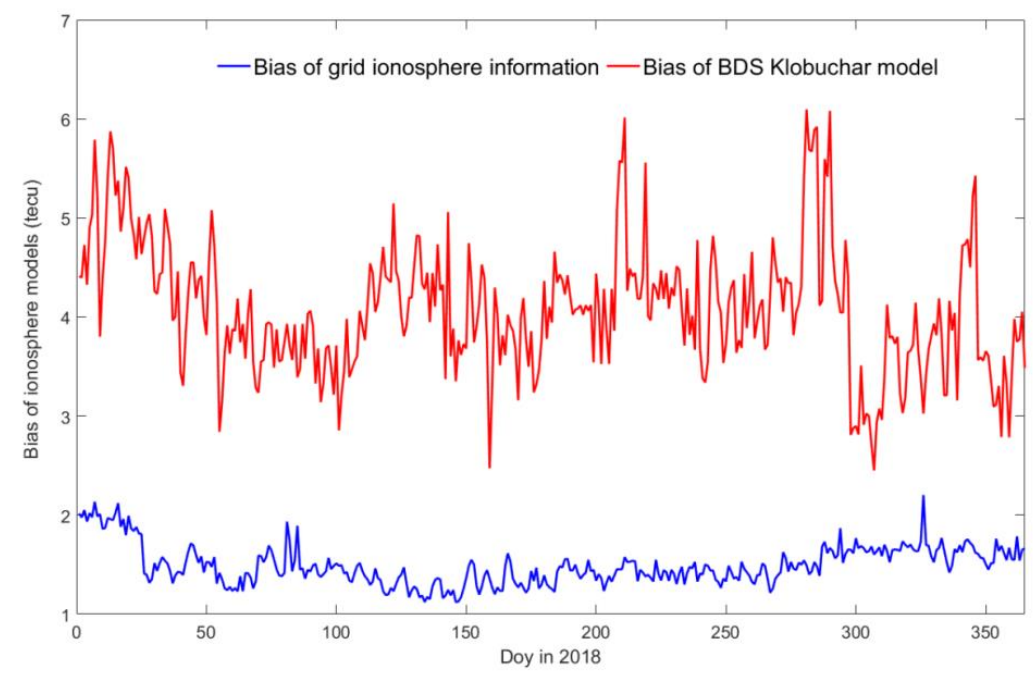

Figure 5. Daily distribution of correction bias of BDS Klobuchar model and ionospheric grid information in 2018.

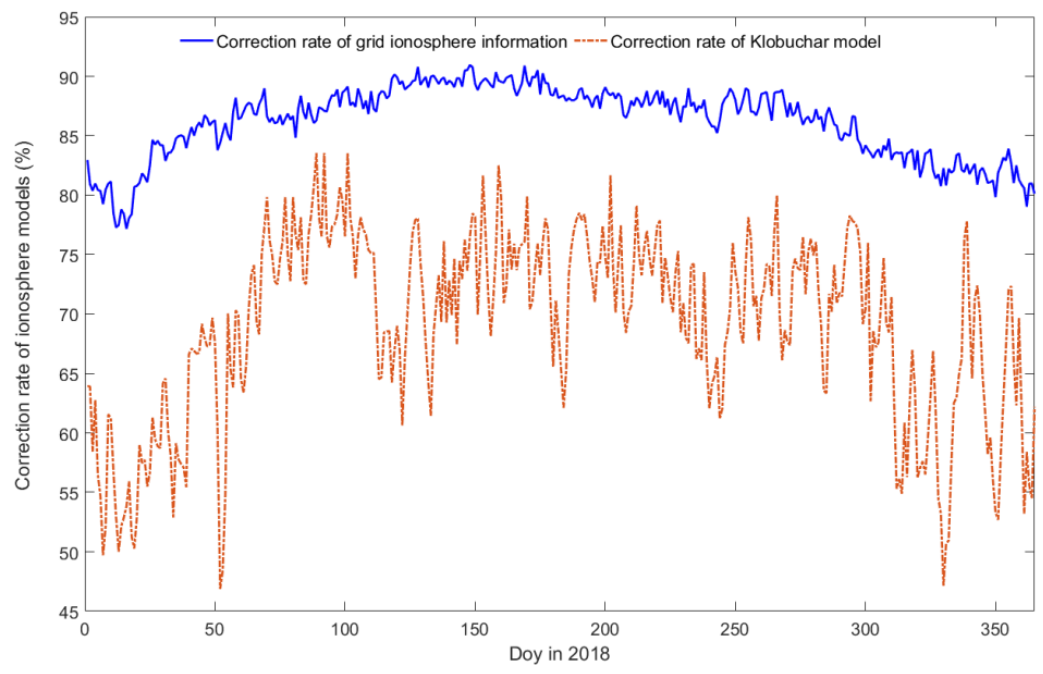

Figure 6. Daily distribution of correction rates of BDS Klobuchar model and ionospheric grid information in 2018.

The correction bias of the BDS Klobuchar model is more active in the fluctuation and larger than those of the ionospheric grid information. The correction bias of the BDS Klobuchar model is in the range of 3TECU to 6TECU, and the correction bias of the ionospheric grid information is only $1.2 \mathrm{TECU}$ to 2TECU. For the BDS Klobuchar model, the correction bias is larger in summer and autumn than in spring and winter, and the variation in autumn and winter are more active in the fluctuation, while the variation in spring and summer is relatively stable. The correction bias of the ionospheric grid information is larger in winter than in other seasons, but the difference is much smaller than the difference between the seasons of the BDS Klobuchar model. The correction bias of the ionospheric grid information is generally stable, which is very likely due to its high precision and high updated frequency.

The correction rate of the ionospheric grid information is greater than of the BDS Klobuchar model, with a difference is about $10 \%$. Their correction rates are higher in summer and autumn than in winter and spring, mainly due to the relatively smaller amount of ionized electrons in winter and spring. The correction rate of the ionospheric grid information is more stable than that of the BDS Klobuchar model. The correction rate of ionospheric grid information is more stable from March to August than in other months. The correction rate of the BDS Klobuchar model is relatively active throughout the year. The main reason may be that the BDS Klobuchar model is based on historical data 
prediction models, and its correction ability is greatly affected by the abnormal changes of the ionosphere.

\subsection{Correction performance change in different period of solar activity}

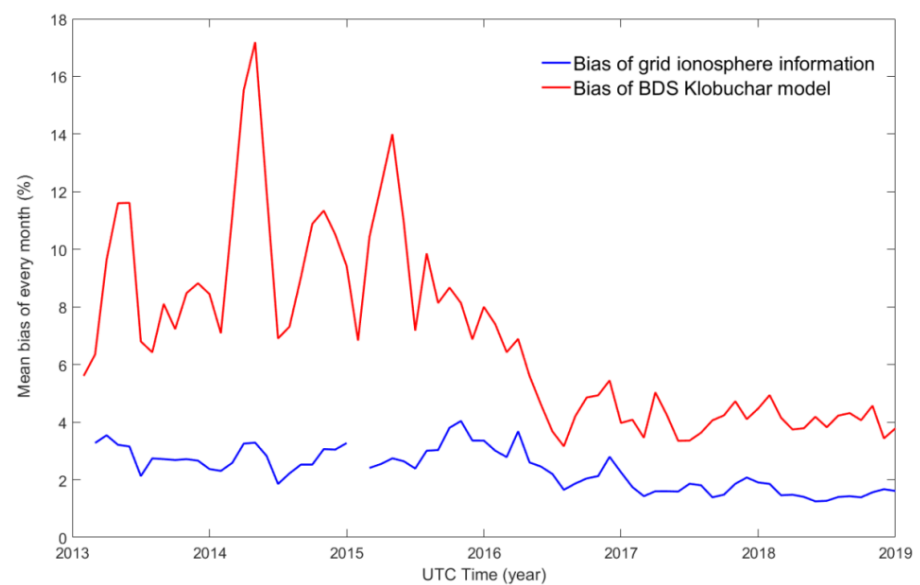

Figure 7. Mean correction bias of every month from 2013 to 2018. The ionospheric grid information data for January 2015 was not obtained for some reason, but the overall analysis and conclusions will not have an impact.

Figure 7 and Figure 8 respectively show monthly mean correction of corrections bias and correction rates of BDS Klobuchar model and ionospheric grid information from 2013 to 2018. In term of correction bias of BDS Klobuchar model and ionospheric grid information, they are higher in values and changes more severely in the active years of solar activity than in the quiet years of solar activity. Furthermore, the BDS Klobuchar model is more affected by solar activity, with a range of 3.5-17 TECU, while ionospheric grid information changes are less affected by solar activity, ranging from 1.5-4 TECU, mainly owing to its rapid update capability. The correction rate of ionospheric grid information is about $12 \%$ higher than that of BDS Klobuchar model. The average correction rate of ionospheric grid information is about $85 \%$, and the average correction rate of BDS Klobuchar model is about $73 \%$. In term of correction rates of BDS Klobuchar model and ionospheric grid information, they change relatively little throughout the solar cycle, but are greatly affected by seasonal anomalies and ionospheric anomalies.

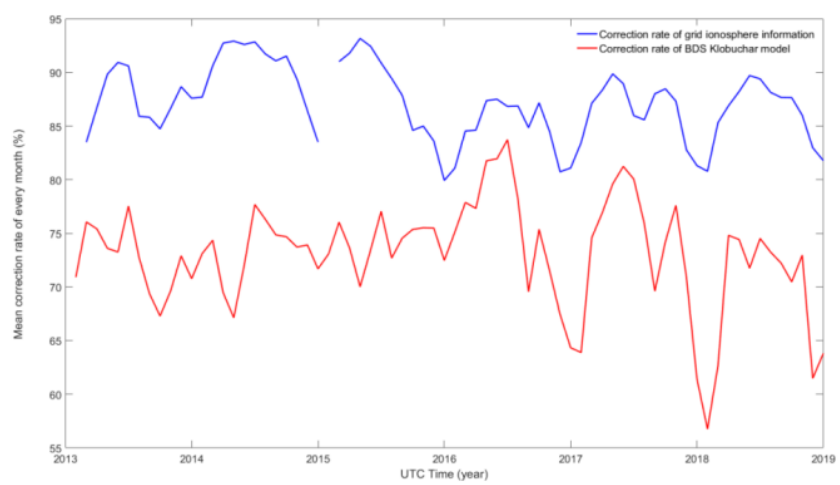

Figure 8. Mean correction rates of every month from 2013 to 2018. The ionospheric grid information data for January 2015 was not obtained for some reason, but the overall analysis and conclusions will not have an impact.

\subsection{Disturbance rejection of ionospheric delay correction of BDS}

Figure 9 shows the ionosphere anomaly occurred on August 31, resulting in a large difference between the ionosphere model delay and the dual frequency delay on September 1. The BDS Klobuchar model can be better corrected the ionosphere delay during the ionosphere anomaly than the Klobuchar model (24h). 


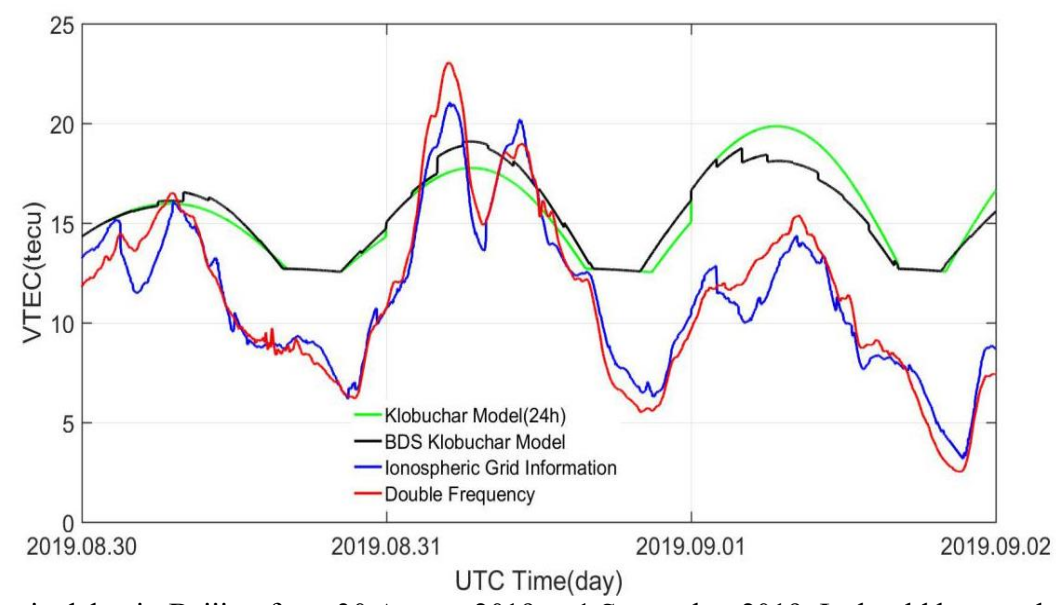

Figure 9. Ionospheric delay in Beijing from 30 August 2019 to 1 September 2019. It should be noted that the Klobuchar model (24h) notes that the BDS Klobuchar model is updated with the same frequency as the GPS Klobuchar model.

Table 1. Statistics of Ionosphere delay Correction rate and VTEC bias in Beijing from 30 August 2019 to 1 September 2019

\begin{tabular}{ccccccc}
\hline \multirow{2}{*}{ UTC Time } & \multicolumn{2}{c}{ Klobuchar Model (24h) } & \multicolumn{2}{c}{ BDS Klobuchar Model } & \multicolumn{2}{c}{ Ionospheric Grid Information } \\
\cline { 2 - 7 } & $\begin{array}{c}\text { VTEC bias } \\
\text { (tecu) }\end{array}$ & $\begin{array}{c}\text { Correction } \\
\text { rate }(\%)\end{array}$ & $\begin{array}{c}\text { VTEC bias } \\
\text { (tecu) }\end{array}$ & $\begin{array}{c}\text { Correction } \\
\text { rate }(\%)\end{array}$ & $\begin{array}{c}\text { VTEC bias } \\
\text { (tecu) }\end{array}$ & $\begin{array}{c}\text { Correction rate } \\
(\%)\end{array}$ \\
\hline $2019 / 8 / 30$ & 3.33 & 63.06 & 3.38 & 62.95 & 0.75 & 93.69 \\
$2019 / 8 / 31$ & 3.25 & 64.82 & 3.01 & 65.51 & 0.81 & 92.98 \\
$2019 / 9 / 1$ & 6.86 & 33.28 & 6.1 & 39 & 0.9 & 90.07 \\
\hline
\end{tabular}

Table 1 shows the ionosphere delay difference and correction rate of Klobuchar model (24h) and BDS Klobuchar model on August 30 are in little difference. During the period of ionosphere anomaly on August 31, BDS Klobuchar model has better antidisturbance ability than Klobuchar model (24h) during the ionosphere anomaly period, because of BDS Klobuchar model produces a set of model parameters every two hours and Klobuchar model (24h) produces a set of parameters every 24 hours. The VTEC bias of BDS Klobuchar model is about 2 tecu less than Klobuchar model (24h), and the correction rate is increased by nearly $1 \%$. On the second day after the ionosphere anomaly, the VTEC bias of BDS Klobuchar model was about 8 tecu less than Klobuchar model $(24 \mathrm{~h})$, and the correction rate is increased by nearly $6 \%$. During the ionosphere anomaly, the grid ionospheric information is basically unaffected and the anti-disturbance ability is relatively strong. At the same time, the BDS Klobuchar model also has a certain anti-disturbance capability compared with the GPS Klobuchar model, which is where other research ignores.

\section{Conclusions}

Comprehensive assessments of the correction performance of BDS Klobuchar model and ionospheric grid information have been made using the data from 2013 to 2018 in the study. The conclusions reached are as follows.

a. The average correction rate of ionospheric grid information is about $85 \%$, and the average correction rate of BDS Klobuchar model is about $73 \%$.

b. Daily correction accuracy of BDS Klobuchar model and ionospheric grid information changes relatively with the solar activity. The correction accuracy of BDS Klobuchar model varies little, and the ionospheric grid information has a single-peak structure. The correction accuracy of the BDS Klobuchar model during the day is higher than that of the nighttime, and the correction bias and rate of the ionospheric grid information are both higher during the day than those at night.

c. The correction accuracy of the BDS Klobuchar model fluctuates greatly with the seasons, while the correction accuracy of the ionospheric grid information fluctuates with seasonal variations. The correction accuracies in summer and autumn are slightly higher than that in winter and spring, which are mainly affected by the seasonal variation of ionospheric electron content.

d. The BDS Klobuchar model has a large change in the solar activity period, and the BDS Klobuchar model correction rate and ionospheric grid information correction accuracy have relatively 
smaller changes in the solar activity period. The influencing factors are mainly seasonal influence and ionospheric disturbance. The influencing factors are mainly seasonal influence and ionospheric disturbance.

e. Ionospheric grid information owns relatively strong anti-disturbance ability, and BDS Klobuchar model also has a definite anti-disturbance capability compared with the GPS Klobuchar model.

\section{References}

1. BeiDou Navigation Satellite System. (2019) Introduction to BeiDou Navigation Satellite System. http://en.beidou.gov.cn/SYSTEMS/System/.

2. BeiDou Navigation Satellite System. (2019) BeiDou Navigation Satellite System Augmentation System. http://www.beidou.gov.cn/xt/zqxt/.

3. Yan, F. and Xie, S. (2000) Ionospheric errors of GPS positioning. Bulletin of surveying and mapping, (9): 10.

4. Liu, C. (2017) Research on Elaboration of GNSS Navigation Ionospheric Model. Zhengzhou: Information Engineering University.

5. CSNO. (2017) Beidou Satellite Navigation System Space Signal In Space Interface Control Document: Open Service Signal B1C (Version 1.0).

6. Xie, G. (2013) Global navigation satellite system principle. Beijing: Electronic Industry Press.

7. Zhang, Q., Zhao, Q., Zhang, H., et al. (2013) Research on BeiDou Navigation Satellite System Ionospheric Model Accuracy. China Satellite Navigation Conference (CSNC) 2013 Proceedings.

8. Sun, M., Yu, J., Hu, Y., et al. (2015) Correction Accuracy Analysis on Ionospheric Model of Beidou System. Journal of surveying and mapping science and technology, (1):27-31.

9. Li, G. and Zhao, M. (2014) Analysis of BDS's Ionospheric Parameter Correction Accuracy. GNSS World of China, 39(05):79-81.

10. Chen, N. and Jia, X. (2014) Precision Assessment of Broadcast Ionospheric Model of COMPASS System Based on Improved CODE Model. China Satellite Navigation Conference (CSNC) 2014 Proceedings.

11. Li, W., Li, M., Hu, Z., et al. (2013) Comparative Analysis of COMPASS and GPS Ionospheric Model on Positioning and Navigation Precision.
China Satellite Navigation Conference (CSNC) 2013 Proceedings.

12. Wu, X., Zhou, J., Tang, B., Gao, Y., Fan, J. (2014) Evaluation of COMPASS ionospheric grid. GPS Solut 18:639-649.

13. Hao, J. and Lv, Z. (1982) Theory and Method of Satellite Positioning. Zhengzhou: Institute of surveying and mapping in PLA information engineering university.

14. Zhang, X., He, H. and Chen, J. (2014) Analysis of TEC Concentration Error Variation. Geomatics \& Spatial Information Technology, (05): 176-179.

15. Jiang, Y., Luo, F., Liu, C., et al. (2019) The Effect of Solar Storm to Ionosphere and Users' Position of BDS. Journal of Navigation and Positioning, 7(2): 68-73.

16. Wang, W., Liu, C., Wang, Y., Jiang, Y., Xu, F. (2019) Analysis on the Influence of Geomagnetic Storm of BDS Pseudo Range Positioning. GNSS World of China, 44(01): 82-88.

17. Liu C., Li H., Feng X., at al. (2017) Advances in Refinements of Klobuchar Ionospheric Model. Journal of surveying and mapping science and technology, 34(05):455-460.

18. CSNO. (2013) Public service of the Beidou satellite navigation system space signals interface control file (2.0).

19. Liu, C., Liu, C., Feng, X., et al. (2018) Quality Evaluation of IGS GIMs Based on the Statistical Characteristics of VTEC/RMS Eigenvalues: A Macro Perspective. Radio Science, 53(6): 790803.

20. Wang, W., Liu, C., Wu, H. (2013) Interpolation Algorithm Analysis of IGS Ionosphere VTEC Product. GNSS World of China, 6: 17-21.

21. Liu, C., Zhu, W., Kong, Y., et al. (2019) Performance Evaluation Method for Ionospheric Grid Information of BDS via Dual-frequency Observations. IOP Conference Series: Earth and Environmental Science, 237(6).

22. Liu, C., Liu, C., Ye, Y., et al. (2016) The Effects on Navigation Precision: An Ionospheric Mapping Functions Perspective. Engineering of Surveying and Mapping, 11: 25-30. 